\title{
Dilemmas and Opportunities Surrounding Participatory Research to Promote Health in Small Towns
}

\author{
Elaine Johannes, Associate Professor and Extension Specialist, School of Family \\ Studies and Human Services, Kansas State University
}

\begin{abstract}
S mall Town Dilemmas: The 2010 census confirmed what most Kansans already knew about the state's population surging in urban areas while declining in small towns and rural areas. At the writing of this article, a number of statesupported efforts are underway to recruit businesses to rural Kansas, to sustain resources and to retain young people. Specifically, Governor Sam Brownback's "Rural Opportunity Zones" (ROZs) are designed to reverse dramatic population declines over the past decade in rural areas of Kansas through income tax exemptions and student loan forgiveness. Even if these steps are successful in the short-term, some experts consider them to be futile in long-term solutions to the "hollowing out the middle".
\end{abstract}

"Hollowing Out the Middle" is the title of a book by sociologists, Patrick Carr and Maria Kefalas (2009), which describes the de-population of rural areas and small towns due to lack of wellpaying jobs, viable schools and adaptive leadership. A conclusion that Carr and Kefalas draw from their twelve month study of small towns in the Midwest is that there is little that policies and public supported programs can do to stem out migration. However, if a small town builds social capital between different sectors, engages young people through leadership opportunities and improves community amenities the town is likely to sustain its unique quality of life and to thrive. But how do leaders in small towns accomplish these results when human, financial and natural capitals are limited? Working through volunteer networks comprised of youth and adults around issues of health for all residents,
Kansas State Research and Extension's Get It - Do It! program has helped small towns move towards sustained quality of life and thriving.

GET IT - DO IT! - Whole Town Participation in Health Promotion

According to the Centers for Disease Control and Prevention (2006), not only is an individual's health affected by their community, but the health of whole communities may be inseparable from the health of individuals and families. Consequently, whole community efforts are most effective in increasing physical activity levels and improving health status among residents. Additionally, Flora and Gillespie (2009) found that targeted programs that increase the social, built and human capitals of communities can result in health and quality of life improvements.

Unfortunately, many small towns and rural areas in the United States lack 
access to the resources or workforce necessary to appropriately adapt health promotion strategies to the unique contextual, cultural features of small towns. This dilemma is compounded when social science researchers and program implementers assume that community members are merely recipients of programs and aren't engaged participants and decision-makers. Successful and sustainable efforts to improve the health of small town citizens require a community development - participatory approach which is distinct from the traditional expert service delivery model.

Cornwell and Jewkes (1995) have made a convincing argument for active participation of communities involved in health programs and/or social science to sustaining results since community members feel no investment in the program or its results. Simply put, program implementers have not given ownership of the program to the people impacted by it. In a participatory process, the people along with the researcher/implementer own the results.

Consequently, Kansas State Research and Extension developed the Get It - Do It! program in 2007, using a community-based participatory approach. The goals of Get It - Do It! are to:

- Foster youth-adult partnerships

- Engage youth in meaningful roles

- Enhance social capital (bonding, bridging, reciprocity)

\section{Community Development Approach}

\section{Expert Delivery}

- Resources from "authority"

- Information dissemination

- Role assignment

- Reliance on external sources of leadership

- Skepticism, confusion

$\mathrm{NCl}$ - What Works: Adapting Evidence-based Programs to fit Your Needs:

http://cancercontrol.cancer.gov/use_what_works/start.htm

\section{Community Development}

- Resources developed and shared

- Information integration

- Incremental change

- Community-based leadership, empowerment

- Community investment and integration research. They contend that the conventional research process is not conducive
- Support local community development vision 


\title{
Participatory and Conventional Research: Process Comparison
}

\author{
Participatory Conventional \\ - Research primarily for - action \\ - Research primarily for - local people \\ - Topic influenced by - local priorities \\ understanding \\ institution \\ other \\ Methodology: \\ - Problem identification - local people \\ researcher \\ - Data collection - local people \\ researcher \\ - Who owns results - shared \\ researcher \\ - What is emphasized - process \\ outcomes \\ Cornwell \& Jewkes (1995). What is Participatory Research? Social Science \& Medicine, Vol. 41, No. 12, pp. 1667-1676
}

- Increase health-promoting opportunities (e.g. park improvements, summer camps, trail development, out-of-school health programs)

Get It - Do It! accomplishes these goals through networks of youth-adult partnerships in small towns that receive seed money, training and support from local intermediaries to increase opportunities for physical activity, improve built environments and strengthen community social capital. Of special focus is increasing the engagement of young people where by increasing their sense of community attachment through community-based participation.

Kansas Get It - Do It! has worked with ten small towns (population ranges from 178 to 2,500) which successfully competed for $\$ 3,000$ grants, recruited youth and adult partners, completed community assessments, participated in 16 hours of health promotion training (e.g. CATCH, NIH's "Media Smart", community park assessment, youth development), implemented projects that promoted healthy activity and engaged in a thoughtful evaluation of their work. Each "Get It - Do It!" community promotes health through their unique micro-projects implemented by youthadult partnerships. The local projects are designed with the "cornerstones of effective and sustainable community health promotion" in-mind. Those cornerstones are:

- Access to healthy foods, places and opportunities to engage in physical activity.

- Establishing meaningful partnerships across generations.

- Understanding the science behind effective health promotion and youth engagement.

- Increasing the capacity of everyone (paid workers and volunteers) participating. 
- Increasing awareness and understanding of the value of healthy living through effective, appropriate and targeted communication.

(from: "Blueprint for Nutrition \& Physical Activity: Cornerstones of a Healthy Lifestyle". Association of State E Territorial Public Health Nutrition Directors, 2008)

Local Get It - Do It! projects involve health (e.g., bike riding down town, food choice during high school lunch, selection of park equipment) at varying degrees in the small towns.

At the state level, Kansas State Research and Extension introduces resources, training, technical assistance and evaluation support to the youth and

\section{Kansas Community-Based Participatory Sites}
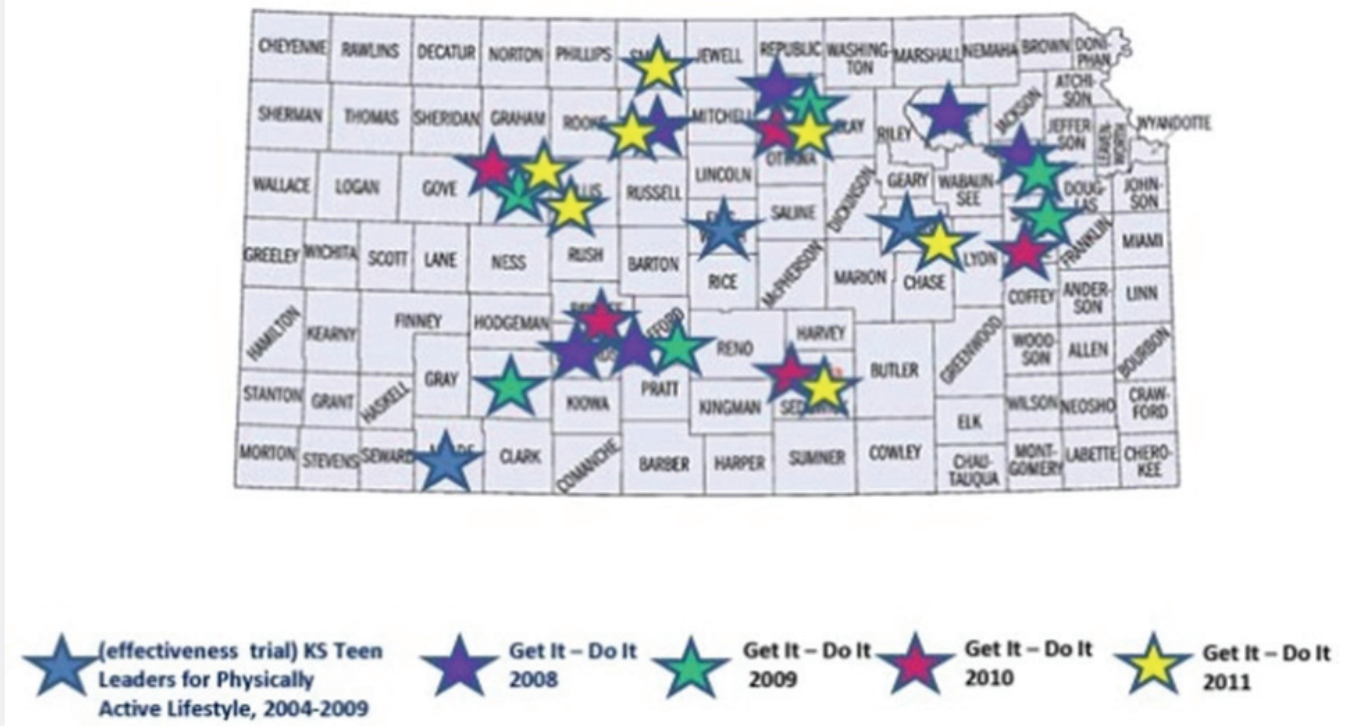

voluntary community improvement organizations (i.e., PRIDE) and youth groups (e.g., schools, scouts, 4-H clubs, faith groups) working together to promote physical activity and healthy eating. Since 2007, youth and adult partners have improved physical activity places (e.g., parks, trails, skate parks), implemented youth-led health promotion activities (e.g., summer health camps, walking clubs, HealthFest celebrations) and addressed policies that impact adult networks. At the local level, Extension professionals serve as intermediaries communicating the results of the project to the media and surrounding towns, providing training as necessary, and helping with Get It - Do It! evaluation (photovoice, observation, survey collection).

In 2010, Get It - Do It! communities involved over 1,500 rural individuals and generated nearly $\$ 75,000$ in-kind through volunteer involvement. Local 
projects have also improved built capital such as town squares, parks, walking trails, skate parks and have used those places to launch health promotion campaigns and activities.

Most importantly, the small towns have discovered that promoting health is a viable way to engage young people and to build leadership skills and community attachment among youth.

Get It - Do It! - Results

In addition to improving infrastructure for health and increasing opportunities to practice healthy behaviors, Get It Do It! communities have learned how to foster youth-adult partnerships which lead to more engaged youth and stronger community social capital. Program evaluations confirm those results.

Get It - Do It! uses a multi-faceted evaluation which includes:

- Surveys - Youth completed pre, post assessments of social capital belonging using Tolan, GormanSmith \& Henry's (2001) Community Belonging survey. Youth and adult mentors also completed the Youth Involvement/Engagement survey (Jones, K., 2006; Jones \& Perkins, 2006) pre, post which measures social capital reciprocity. At the end of the project, groups of youth from each community participated in an interactive community mapping activity (Emery, Baker, Calvert, Enfield \& Williams, in press) which assesses social capital impact.

- Observations - Third party observers, trained to identify evidence of youth involvement based on Hart's (1992) model of youth participation, were deployed quarterly in the communities to observe youth-adult interactions during project activities and community events.

- Photovoice - Youth, provided with cameras and a secure website for downloading/posting, reported activities and results of projects through photos.

- Intermediary reports - Telephone conference calls to local Extension personnel serving as intermediaries/key-informants provided information about the organization, process and sustainment of the project.

Survey results thus far for 2011 indicate that:

- Youth participant feelings of loyalty to their towns increased.

- Youth participant feelings of belonging increased.

- Youth participant desire to live in a small town as adults increased.

- Youth participants developed new skills by helping one another through the projects.

- Youth and adults established effective partnerships, where none existed previously, through the projects.

These findings give positive direction to rural areas and small towns wishing to recruit, re-energize and retain young people as community leaders and engaged citizens.

Lessons Learned: Dilemmas Lead to Opportunities 
Local Get It - Do It! projects spring from the dreams and drive of community volunteers - young and old. That volunteer drive is essential for engaging youth, for sustaining the project in midcourse, and involving the whole town. In most cities, involvement by everyone may be impossible, but in small towns everyone is involved because the town depends on it. The Get It - Do It! project of Grinnell, KS is a good example. At the end of the 2010 Get It - Do It! project in Grinnell the town had a picnic to discuss what was accomplished for the year and to demonstrate the new park equipment that was designed for abled and not abled alike. The community picnic was attended by 80 people which were $30 \%$ of the town's population of 269. Imagine a city getting one-third of its total residents in one place for over four hours to celebrate with each other, welcome new residents, learn about health from young people and plan more opportunities for health!

One must be realistic, however because community-based participatory projects pose dilemmas that can become challenges. Implementers must keep inmind that:

- Working with local people is far from easy because word travels quickly and everyone knows everyone.

- Not all are motivated to be involved so the leaders (youth and adults) can become exhausted by the project.

- Enthusiasm for the project may wane, and others may be hesitant to step-in because they don't want to offend the "champion".

- If the "champion" leaves the community, then others may follow.

- Small, rural communities are complex given the kinship connections, meaning of historical events and the on-going threat of depopulation.

Simply, the researcher and program implementer must be aware (and be appreciative) of those dynamics, must communicate clearly and frequently with everyone involved. The researcher must also be willing to allow the research agenda to be secondary to the primary objective of building community social, human and built capital through participation.

There are opportunities when working with small towns that large cities don't provide. Specifically, from an Extension professional's standpoint, Fran Richmond, Director of the Frontier Extension District, said that "The Get It - Do It!" program is a program with great potential for replication across the state. Many communities could benefit from the educational information regarding process and partnerships. The seed money to help small towns follow through with their dreams is important and needed. When communities are taught planning skills, and given support to reach their goals, great things happen."

Though Kansas State Research and Extension provided the impetus through Get It - Do It! to improve health and strengthen social capital, it has been up 
to the youth and adults to design and implement projects that are informed by science and tailored to the uniqueness of their small town. An important lesson learned by this author through these projects is how important selfdetermination is.

In the words of Joan Nothern, Glasco PRIDE, "The concept of each community building its own project to meet its own defined needs conveys a respect that really promotes the will to deliver and deliver again."

\section{$\underline{\text { References }}$}

Association of State \& Territorial Public Health Nutrition Directors (2008). Blueprint for Nutrition \&Physical Activity: Cornerstones of a Healthy Lifestyle. Retrieved from: www.movingtothefuture.org

Carr, P. and Kefalas, M., (2009). Hollowing Out the Middle: The Rural Brain Drain and What It Means for America. NY: Beacon Press.

Cornwell, A. and Jewkes, R. (1995). What is Participatory Research? Social Science \& Medicine, Vol. 41, No. 12, pp. 1667-1676

Emery, M. Baker,B., Calvert,M. Enfield, R. and Williams, B. (in press). Using the Community Capitals to Map Program Impact. Community Development Practice.

Flora,C. and Gillespie, A.H., (2009). Making Healthy Choices to Reduce Childhood Obesity: Community Capitals and Food and Fitness. Journal of Community Development Society, 40 (2), pp. 114-122.

Hart, R. (1992). Ladder of Youth Participation: Children's Participation: From Tokenism to Citizenship. UNICEF. Retrieved from:

http://www.unicef.org/adolescence/files/Partic ipation_Rights_of_Adolescents_Rajani_2001.pdf

Jones, K. (2006). Determining the Quality of Youth-Adult Relationships Within Community-Based Youth Programs. Journal of Extension, 43 (5). Retrieved from: www.joe.org/joe/2006october/a5.php

Jones, K. and Perkins, D., (2006). Youth and Adult Perceptions of Their Relationships Within Community-Based Youth Programs. Youth $\mathcal{E}$ Society, 38 (90), pp. 90-109.

National Cancer Institute (2007). What Works: Adapting Evidence-based Programs to fit Your Needs. Retrieved from:

http://cancercontrol.cancer.gov/use what wor ks/start.htm

Tolan,P.H., Gorman-Smith, D., and Henry, D.B. (2001). Chicago Youth Development Study Community and Neighborhood Measure: construction and reliability technical report. Families andCommunities Research Group, Department of Psychiatry, The University of Illinois at Chicago. Retrieved from:

http://www.cdc.gov/ncipc/pubres/pdf/YV/CDC YV SecIV.pdf 